\title{
ERRATUM
}

\section{Modelling film flows down a fibre - ERRATUM}

\author{
C. Ruyer-Quil, P. Trevelyan, F. Giorgiutti-Dauphiné, C. Duprat \\ and S. Kalliadasis \\ doi:10.1017/S0022112008001225, Published online by Cambridge University Press, \\ 30 April 2008
}

In Ruyer-Quil et al. (2008), author P. M. J. Trevelyan's name was incorrectly given as P. Treveleyan.

This has been corrected in both the online PDF and HTML versions of this article. The Press apologises for this error.

\section{REFERENCE}

Ruyer-Quil, C., Trevelyan, P. M. J., Giorgiutti-Dauphiné, F., Duprat, C. \& Kalliadasis, S. 2008 Modelling film flows down a fibre. J. Fluid Mech. 603, 431-462. 